\title{
PARTICIPAĈ̃O RELATIVA DO MUNICÍPIO DE SÃO PAULO NAS EMISSÕ̃ES DE POLUENTES VEICULARES DA REGIÃO METROPOLITANA DE SÃO PAULO, NO PERÍODO DE 2006 A 2017
}

\author{
Cristiane Dias ${ }^{1}$, Marcelo Pereira Bales ${ }^{1}$, Silmara Regina da Silva ${ }^{1}$ \\ ${ }^{1}$ CETESB (Companhia Ambiental do Estado de São Paulo) \\ E-mails: cdias@sp.gov.br, mbales@sp.gov.br, silmsilva@sp.gov.br
}

\section{RESUMO}

De acordo com a metodologia da Cetesb, a frota circulante de caminhões e ônibus do município de São Paulo correspondeu no ano de 2017 à cerca de $22 \%$ da frota da região metropolitana de São Paulo. Este trabalho apresenta a participação nas emissões de poluentes desses veículos do município de São Paulo em relação às emissões da região metropolitana de São Paulo, considerando o período de 2006 a 2017. Assim os esforços no controle e na redução das emissões de poluentes veiculares na cidade de São Paulo, estabelecidos pela lei municipal 16.802/2018 podem ter impacto significativo. A lei trata sobre a redução de emissões de poluentes locais e gases de efeito estufa na frota de transporte coletivo e em outros veículos que operam no município de São Paulo. Os poluentes considerados neste estudo foram os óxidos de nitrogênio $\left(\mathrm{NO}_{\mathrm{x}}\right)$, o material particulado (MP) e o dióxido de carbono equivalente $\left(\mathrm{CO}_{2} \mathrm{eq}\right)$, conforme previstos na lei. Os resultados indicaram a participação relativa do município de São Paulo em torno de 53\% nas emissões de caminhões e ônibus, de óxidos de nitrogênio $\left(\mathrm{NO}_{\mathrm{x}}\right)$ e de material particulado (MP); e de $52 \%$ nas emissões de $\mathrm{CO}_{2}$ eq do município nas emissões da RMSP. Foi também analisada a possível introdução de veículos da fase P8 substituindo a frota circulante de ônibus do município, com idade superior a dez anos; e a troca da frota de ônibus de fretamento da região metropolitana de São Paulo, em 2017.

\section{INTRODUÇÃO}

De acordo com Dapper, S.N. et al [1] existem diversos efeitos negativos causados pelas emissões de poluentes atmosféricos no meio ambiente e na qualidade de vida das pessoas. Além dos impactos adversos na saúde da população em geral, os problemas causados pela poluição do ar também geram impactos negativos no que se refere à perspectiva econômica e social, como por exemplo, a queda da produtividade agrícola, o aumento de custos dos sistemas de saúde, a maior vulnerabilidade de populações carentes, etc.

Estudo da Agência Ambiental Americana (USEPA) [2] demonstrou que a exposição aos poluentes veiculares podem causar problemas cardíacos e pulmonares, 
podendo levar a mortes prematuras, especialmente considerando idosos e crianças pequenas, ou indivíduos com baixa imunidade.

Como indica a tabela 1 no ano de 2017, no município de São Paulo a frota total circulante correspondeu à cerca de $63 \%$ da frota da região metropolitana de São Paulo. Sendo que a região metropolitana de São Paulo é composta por 39 municípios, a frota somente do município de São Paulo representa mais do que a metade da frota total da região metropolitana.

Tabela 1. População e frota total circulante no estado de São Paulo, na região metropolitana de São Paulo e no município de São Paulo, no ano de 2017

\begin{tabular}{lllc}
\hline Região & $\begin{array}{l}\text { Número de } \\
\text { municípios }\end{array}$ & população & Frota circulante \\
\hline Estado & 645 & 43.674 .533 & 15.234 .673 \\
RMSP & 39 & 20.717 .505 & 7.282 .803 \\
Cidade de São & 1 & 12.107 .201 & 4.575 .972 \\
Paulo & & & \\
\hline
\end{tabular}

Fonte: [3] CETESB (2018)

O objetivo deste trabalho é apresentar a participação das emissões de poluentes de ônibus e caminhões no município de São Paulo em relação às emissões da região metropolitana de São Paulo, considerando o período de 2006 a 2017.

A lei municipal 16.802/2018 [4] diz que os operadores dos serviços de transporte coletivo de ônibus, integrantes do Sistema de Transporte Urbano de Passageiros do Município de São Paulo, bem como as empresas que prestam serviços de coleta de Resíduos Sólidos Urbanos e Hospitalares (lixo) no município de São Paulo, deverão promover a redução progressiva das emissões de dióxido de carbono $\left(\mathrm{CO}_{2}\right)$ de origem fóssil, e de poluentes tóxicos emitidos na operação de suas respectivas frotas, por meio da utilização gradual de combustíveis e tecnologias mais limpas e sustentáveis.

Deste modo, pode-se considerar que a introdução da fase P8 do PROCONVE pode contribuir com a redução das emissões de poluentes tóxicos pela frota circulante de ônibus do município de São Paulo. De acordo com os novos limites de emissões da fase P8 do PROCONVE [5], estima-se que as emissões de óxidos de nitrogênio $\left(\mathrm{NO}_{\mathrm{x}}\right)$ poderiam ser reduzidas em torno de $80 \%$ e as emissões de material particulado podem ser reduzidas em $50 \%$, para os veículos pesados. 


\section{INFORMAÇÕES GERAIS}

O estado de São Paulo teve a população estimada em 43,7 milhões de pessoas em 2017 [3] e a frota circulante total de 15,2 milhões de veículos em 2017, de acordo com a metodologia adotada pela Cetesb. A figura 1 apresenta a evolução da frota circulante do estado de São Paulo, dos ciclos Otto e Diesel, no período de 2006 a 2017.

Figura 1. Evolução da frota circulante total (ciclos Otto e Diesel) no estado de São Paulo, no período de 2006 a 2017.

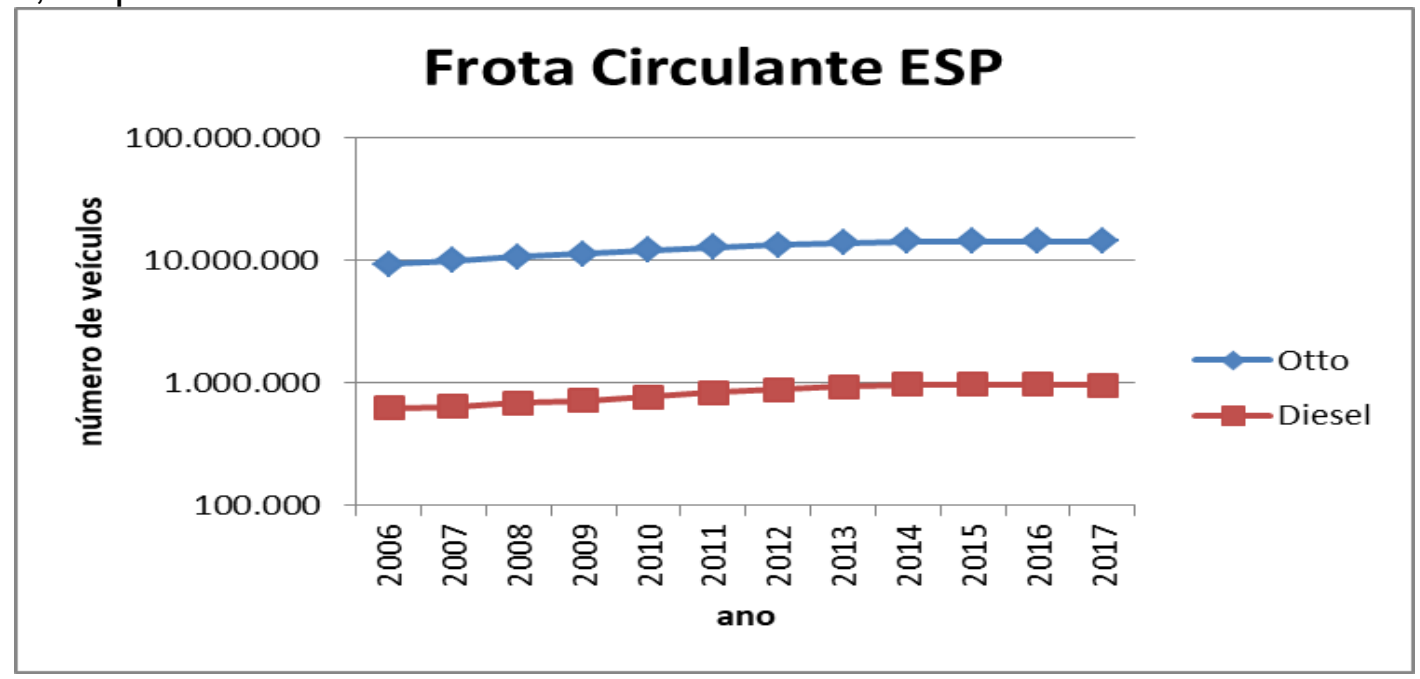

A região metropolitana de São Paulo teve a população estimada em 20,7 milhões de pessoas em 2017 e a frota circulante total de 7,3 milhões de veículos em 2017. A figura 2 apresenta a evolução da frota circulante total na região metropolitana de São Paulo, dos ciclos Otto e Diesel, no período de 2006 a 2017. Houve um crescimento de cerca de $53 \%$ das frotas circulantes do ciclo Otto e Diesel, na região metropolitana de São Paulo no período.

Figura 2. Evolução da frota circulante total (ciclos Otto e Diesel) na Região Metropolitana de São Paulo, no período de 2006 a 2017.

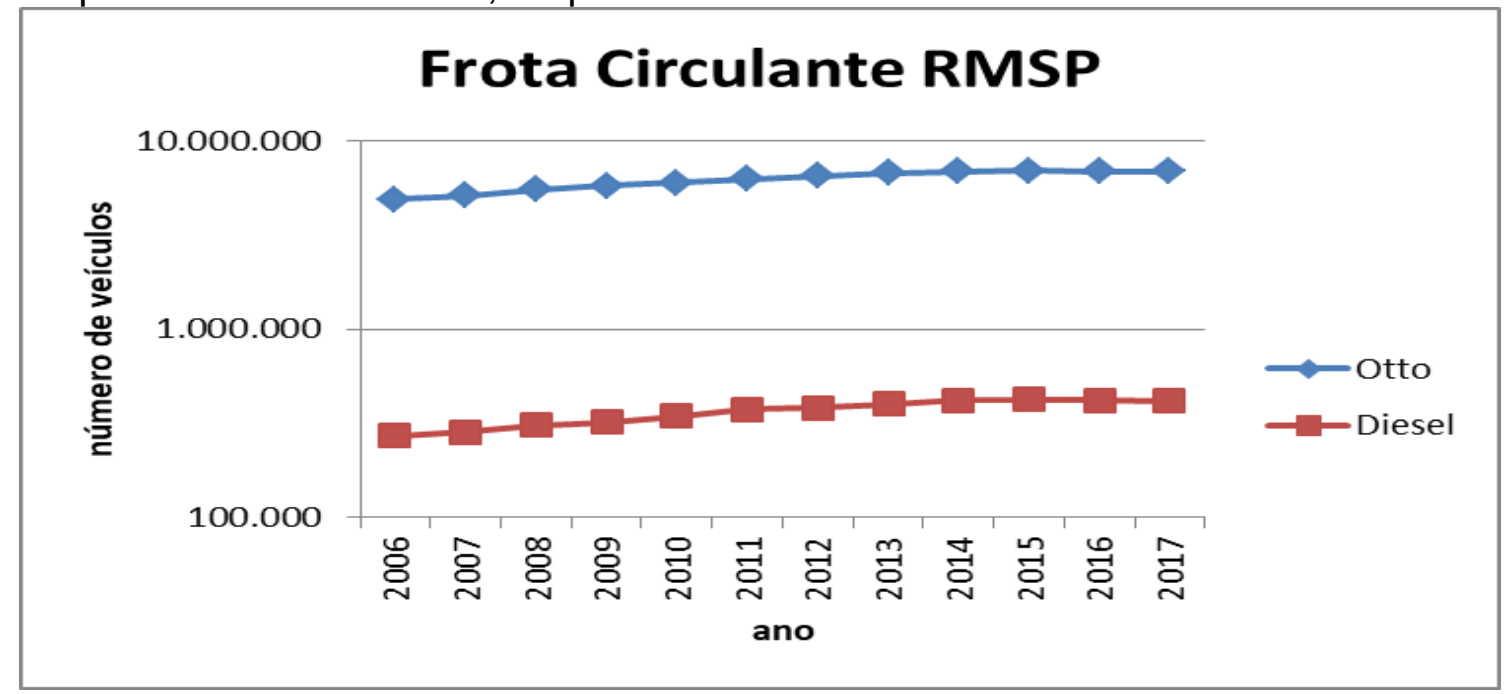


O município de São Paulo teve a população estimada em 12,1 milhões de pessoas em 2017 e a frota circulante total de 4,6 milhões de veículos em 2017. A figura 3 apresenta a evolução da frota circulante total do município de São Paulo, dos ciclos Otto e Diesel, no período de 2006 a 2017. Houve um crescimento de cerca de $27 \%$ das frotas circulantes do ciclo Otto e Diesel, no município de São Paulo no período.

Figura 3 Evolução da frota circulante total (ciclos Otto e Diesel) no município de São Paulo, no período de 2006 a 2017.

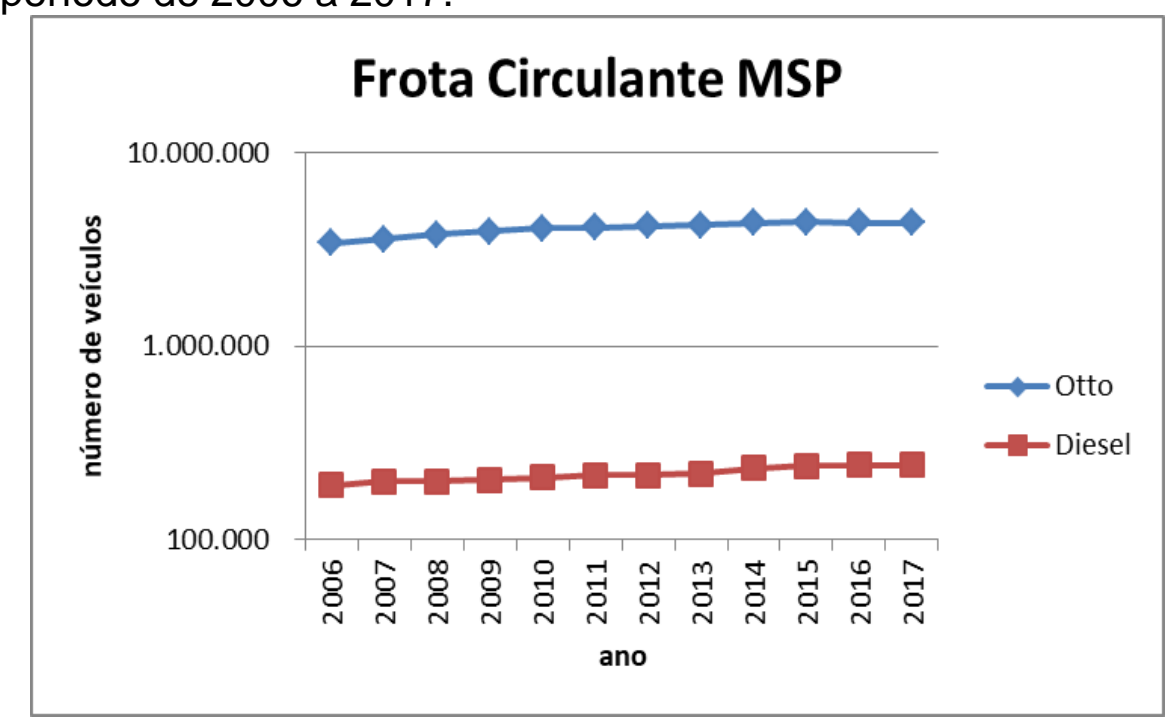

A figura 4 indica a evolução do consumo de combustíveis fósseis e renováveis no município de São Paulo, em toneladas equivalentes de petróleo (TEP), no período de 2006 a 2017. Pode-se observar que o consumo de combustíveis fósseis é complementar ao consumo de combustíveis renováveis no período analisado.

Figura 4. Evolução do consumo aparente de combustíveis fósseis e renováveis no município de São Paulo, em toneladas equivalentes de petróleo (TEP), no período de 2006 a 2017.

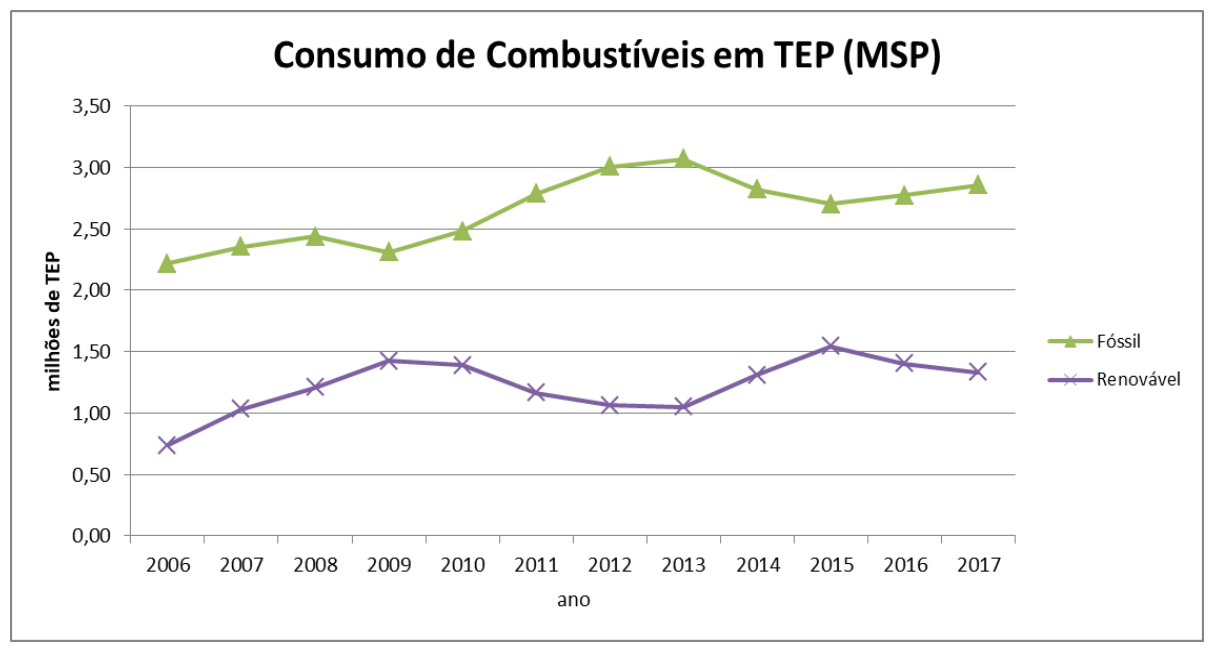

Fonte: SÃO PAULO (Estado) [6] 
As estimativas de emissões veiculares publicadas anualmente pela CETESB demonstram que as emissões são fundamentalmente dependentes dos fatores de emissão, da intensidade de uso ou quilometragem anual do veículo e do consumo de combustíveis da área ou região de interesse.

\section{METODOLOGIA}

O cálculo é dividido em duas grandes etapas: a primeira consiste na caracterização da frota circulante, envolvendo idade da frota, perfil de sucateamento e consumo do combustível para a correção da intensidade de uso. A segunda etapa, referente ao cálculo efetivo das emissões, considera os fatores de emissão específicos para cada poluente.

Os poluentes considerados são:

$>$ Óxidos de nitrogênio $\left(\mathrm{NO}_{\mathrm{x}}\right)$ : para ônibus e caminhões que usam óleo diesel;

> Material particulado (MP): para ônibus e caminhões que usam óleo diesel; e

> Dióxido de Carbono equivalente $\left(\mathrm{CO}_{2}\right.$ eq): composto pelos gases $\mathrm{CO}_{2}$, $\mathrm{CH}_{4}$ e $\mathrm{N}_{2} \mathrm{O}$ ponderados pelo GWP(Potencial de aquecimento global), em um horizonte de 100 anos, para ônibus e caminhões que usam óleo diesel.

O óleo diesel tem de 2\% a 10\% de biodiesel em sua composição, de 2006 a 2017. Para o cálculo das emissões veiculares é necessário obter dados provenientes de diversas bases de dados como:

1. Licenciamento anual de veículos novos nos últimos 40 anos, da Associação Nacional dos Fabricantes de Veículos Automotores [7].

2. Consumo anual de óleo diesel, da Agência Nacional do Petróleo, Gás Natural e Biocombustíveis [8].

3. Taxas de sobrevivência de veículos (curvas de sucateamento) [3].

4. Intensidade de uso de referência ( $\mathrm{km} / \mathrm{ano}$ ), da Companhia Ambiental do Estado de São Paulo [9]

5. Fatores médios de emissão de veículos novos por categoria, por poluente e por ano de fabricação [3].

6. Dados de autonomia dos veículos por categoria e por ano de fabricação [3].

7. Dados da frota de veículos registrada, por categoria e por ano de fabricação (para o cálculo de emissões de regiões ou de municípios) [10].

A equação geral de cálculo das emissões veiculares utilizada é a equação 1:

$$
E=F e \times F r \times l u
$$

Onde:

- E é a taxa anual de emissão do poluente considerado (g/ano); 
- Fe é o fator de emissão do poluente considerado. É específico para cada tipo de veículo, idade e combustível utilizado. É expresso em massa de poluentes emitida por quilômetro percorrido $\left(\mathrm{g}_{\text {poluente }} / \mathrm{km}\right)$;

- Fr é a frota de veículos circulante para cada tipo de veículo, idade e combustível considerado. É expressa em número de veículos; e

- Iu é a intensidade de uso do veículo. É específico para cada tipo e idade do veículo, expressa em quilometragem anual percorrida ( $\mathrm{km} / \mathrm{ano})$.

Os fatores de emissão por categoria/combustível e poluente resultam da média ponderada de ensaios de emissões dos modelos de veículos novos mais vendidos, para o acompanhamento do PROCONVE/PROMOT[11]

A frota em circulação compreende todos os veículos com até 40 anos de fabricação. Para este trabalho, considerou-se que os veículos das frotas circulantes se encontram em condições adequadas de manutenção, de acordo com as recomendações dos fabricantes. A figura 5 apresenta a taxa de sobrevivência empregada no cálculo da frota circulante no estado de São Paulo, na região metropolitana de São Paulo e no município de São Paulo, no período de 2006 a 2017.

Figura 5. Taxa de sobrevivência dos veículos por categoria, em função da idade até 40 anos.

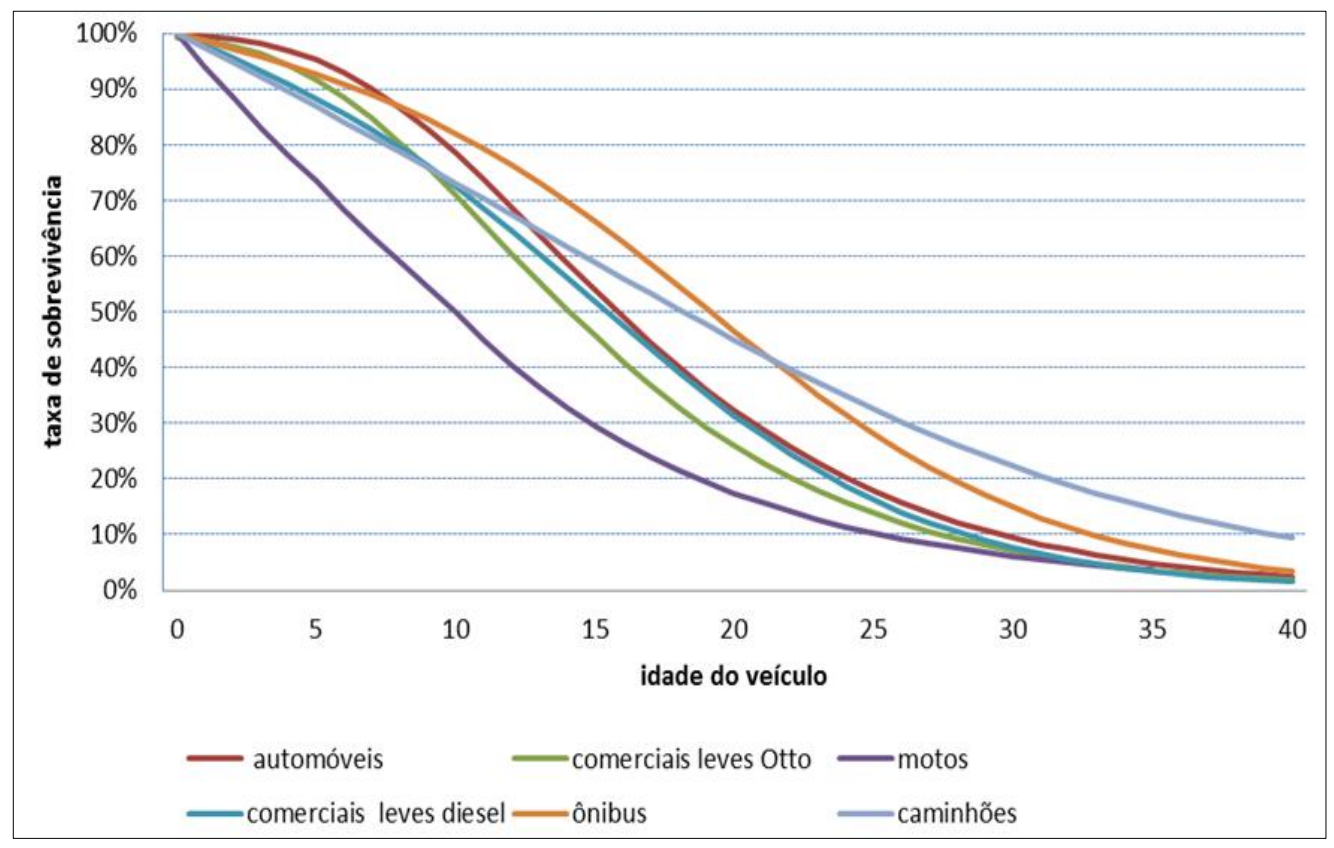

Fonte: [3] CETESB (2018)

A intensidade de uso de referência representa a quilometragem ou a distância percorrida por ano e por tipo de veículo. Esta variável representa uma frota diversificada, onde existem veículos leves e pesados, além de motocicletas, e cada categoria com um perfil próprio de utilização. Desta forma, a variável intensidade de 
uso de referência precisa ser ajustada em função do consumo de combustíveis observado na região de interesse.

Foram utilizadas estimativas de intensidade de uso de referência ou quilometragem anual percorrida por categoria, variando em função da idade do veículo. A partir dos valores de intensidade de uso de referência e do volume de combustíveis consumidos nas áreas estudadas foi realizado o ajuste da intensidade de uso ou da quilometragem anual percorrida.

\section{RESULTADOS E DISCUSSÕES}

A figura 6 indica a evolução das emissões de óxidos de nitrogênio $\left(\mathrm{NO}_{\mathrm{x}}\right)$ por caminhões e ônibus no município de São Paulo e na região metropolitana de São Paulo (RMSP), no período de 2006 a 2017. As emissões de óxidos de nitrogênio $\left(\mathrm{NO}_{\mathrm{x}}\right)$ do município representam em torno de $53 \%$ das emissões da RMSP no período analisado. Houve uma queda de $32 \%$ nas emissões de óxidos de nitrogênio $\left(\mathrm{NO}_{\mathrm{x}}\right)$ de 2006 a 2017 no município de São Paulo e também na região metropolitana de São Paulo (RMSP) no mesmo período.

Figura 6. Evolução das emissões de óxidos de nitrogênio $\left(\mathrm{NO}_{\mathrm{x}}\right)$, por caminhões e ônibus no município de São Paulo (MSP) e na região metropolitana de São Paulo (RMSP) no período de 2006 a 2017.

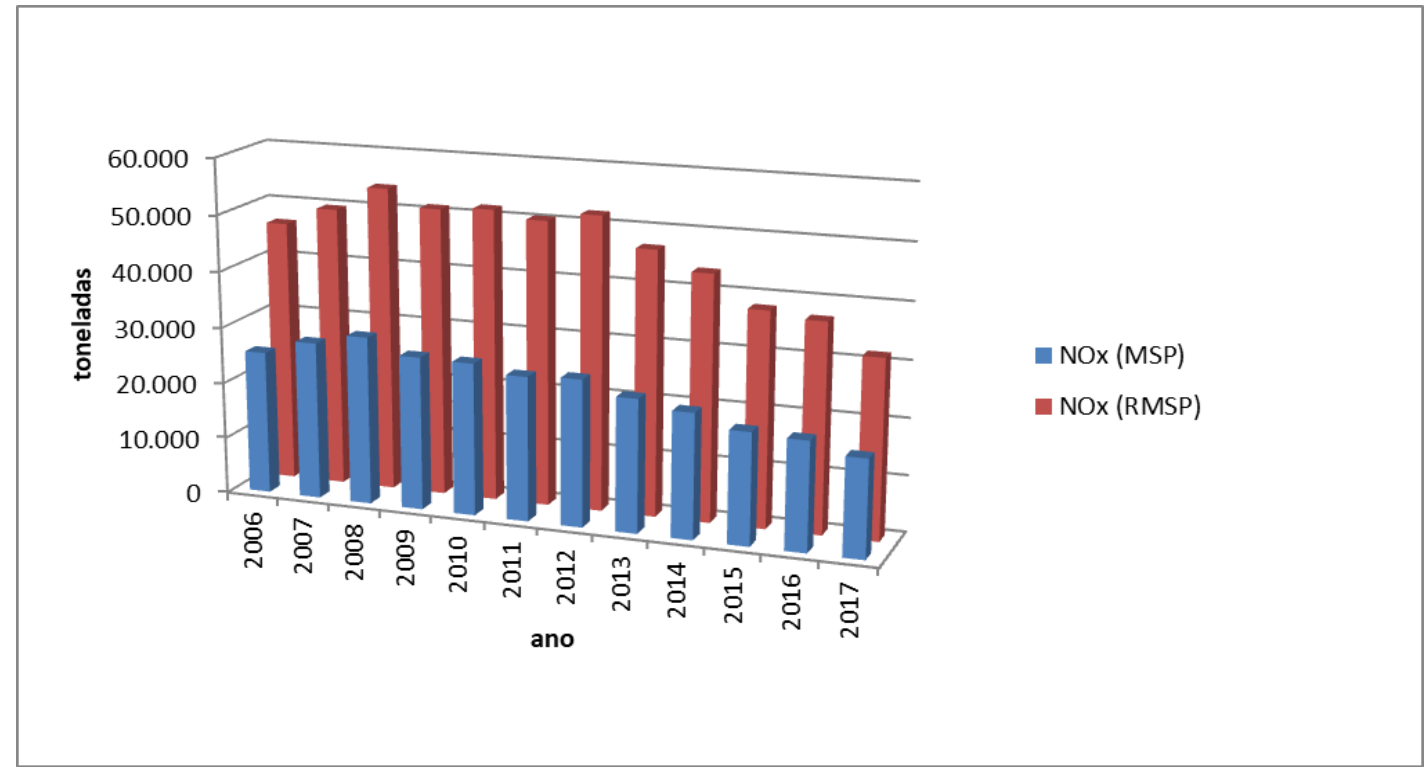

A figura 7 indica a evolução das emissões de material particulado (MP) por caminhões e ônibus no município de São Paulo e na região metropolitana de São Paulo (RMSP), no período de 2006 a 2017. As emissões de material particulado (MP) do município representam em torno de 53\% das emissões da RMSP no período analisado. Houve uma queda de $56 \%$ nas emissões de material particulado (MP) de 2006 a 2017 no município de São Paulo e na região metropolitana de São Paulo (RMSP). 
Figura 7. Evolução das emissões veiculares de material particulado (MP) por caminhões e ônibus no município de São Paulo (MSP) e na região metropolitana de São Paulo (RMSP) no período de 2006 a 2017.

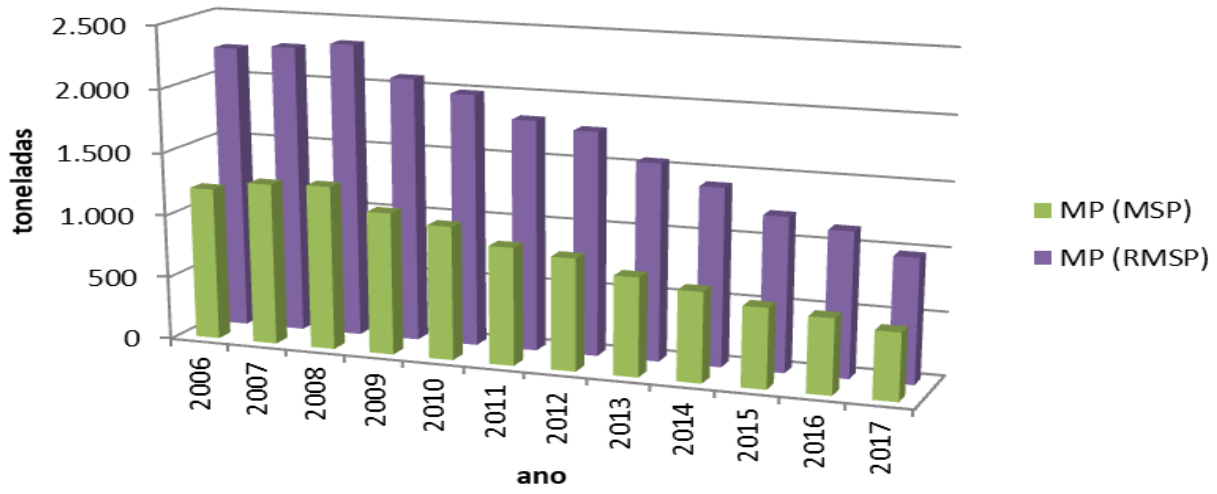

A figura 8 indica a evolução das emissões de dióxido de carbono equivalente $\left(\mathrm{CO}_{2}\right.$ eq) por caminhões e ônibus no município de São Paulo e na região metropolitana de São Paulo (RMSP), no período de 2006 a 2017. As emissões de dióxido de carbono equivalente $\left(\mathrm{CO}_{2}\right.$ eq) do município representam em torno de $52 \%$ das emissões da RMSP no período analisado. Houve um aumento de $21 \%$ nas emissões de dióxido de carbono equivalente $\left(\mathrm{CO}_{2}\right.$ eq) de 2006 a 2017 no município de São Paulo, e de 22\% na região metropolitana de São Paulo (RMSP).

Figura 8. Evolução das emissões veiculares de dióxido de carbono equivalente $\left(\mathrm{CO}_{2}\right.$ eq) por caminhões e ônibus, no município de São Paulo (MSP) e na região metropolitana de São Paulo (RMSP) no período de 2006 a 2017.

\section{$\mathrm{CO}_{2}$ equivalente}

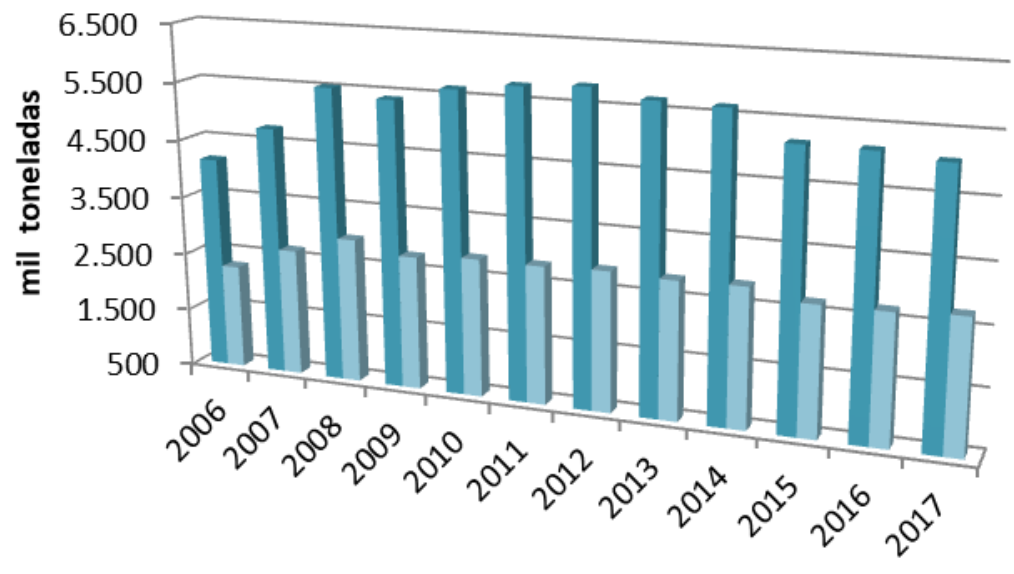

- CO2mil t (RMSP)

- CO2 mil t(MSP)

ano 


\subsection{Considerações incluindo a fase P8 do PROCONVE para o município de São Paulo}

Foi considerado o cenário (1) onde, na frota circulante de ônibus do município de São Paulo, seriam trocados os ônibus da frota (urbanos, micro-ônibus e rodoviários) com idade superior a dez anos, por veículos novos pertencentes à fase P8 do PROCONVE[11]. Adotou-se que os fatores médios de emissão de $\mathrm{NO}_{x}$ seriam diminuídos em $80 \%$ e os fatores médios de emissão de material particulado (MP) diminuiriam $50 \%$. A figura 9 ilustra a frota circulante obtida após a troca dos veículos velhos por novos, com tecnologias atualizadas de controle de emissões. Seriam substituídos 6.993 ônibus urbanos, 1.531 micro-ônibus e 3.742 ônibus rodoviários, totalizando a troca de 12.266 veículos antigos.

Figura 9. Distribuição da frota circulante de ônibus do município de São Paulo, considerando a introdução de veículos da fase P8 do PROCONVE.

\section{Distribuição da frota de ônibus por fase do PROCONVE}

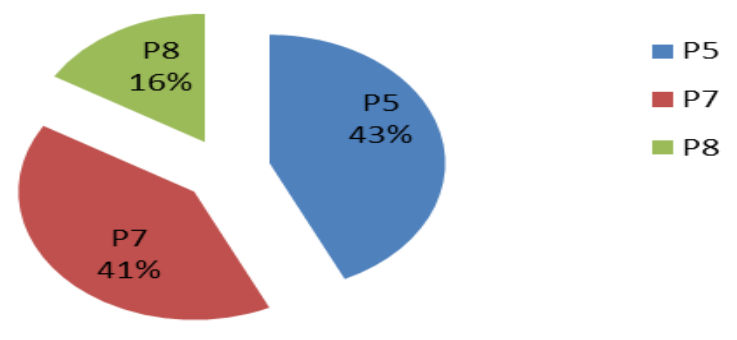

A tabela 2 apresenta os resultados obtidos nas reduções de emissões de óxidos de nitrogênio $\left(\mathrm{NO}_{\mathrm{x}}\right)$ no município de São Paulo. Foi utilizado o ano base de 2017 para este cenário.

Tabela 2. Reduções de emissões de óxidos de nitrogênio $\left(\mathrm{NO}_{\mathrm{x}}\right)$ no município de São Paulo (ano base: 2017), com a introdução de veículos novos fase P8.

\begin{tabular}{|c|c|c|c|c|}
\hline \multicolumn{2}{|c|}{ Município de São Paulo (ano base 2017) } & antes da troca da frota & depois da troca da frota & Redução \\
\hline \multicolumn{2}{|c|}{ Categoria/Poluente } & NOx (toneladas) & NOx (toneladas) & NOx (toneladas) \\
\hline \multirow{3}{*}{ Ônibus } & Urbanos & 5.945 & 3.302 & 2.644 \\
& Micro-ônibus & 427 & 217 & 210 \\
& Rodoviários & 1.365 & 746 & 620 \\
\hline
\end{tabular}

A tabela 3 apresenta os resultados obtidos nas reduções de emissões de material particulado (MP) no município de São Paulo. Foi utilizado o ano base de 2017 para este cenário. 
Tabela 3. Reduções de emissões de material particulado (MP) no município de São Paulo (ano base: 2017), com a introdução de veículos novos fase P8.

\begin{tabular}{|c|c|c|c|c|}
\hline \multicolumn{2}{|c|}{ Município de São Paulo (ano base 2017) } & antes da troca da frota & depois da troca da frota & Redução \\
\hline \multicolumn{2}{|c|}{ Categoria/Poluente } & MP (toneladas) & MP (toneladas) & MP (toneladas) \\
\hline \multirow{4}{*}{ Ônibus } & Urbanos & 160 & 52 & 108 \\
\hline & Micro-ônibus & 11 & 4 & 7 \\
\hline & Rodoviários & 41 & 11 & 30 \\
\hline & & & & 146 \\
\hline
\end{tabular}

\subsection{Considerações incluindo a fase P8 do PROCONVE para a Região Metropolitana de São Paulo}

Considerou-se o cenário (2) nas tabelas 4 e 5, onde na frota circulante de ônibus da região metropolitana de São Paulo, seriam trocados os ônibus antigos da frota de fretamento de ônibus intermunicipais na região metropolitana de São Paulo [12] por veículos novos pertencentes à fase P8 do PROCONVE[11]. Adotou-se que os fatores médios de emissão de $\mathrm{NO}_{x}$ seriam diminuídos em $80 \%$ e os fatores médios de emissão de material particulado (MP) diminuiriam 50\%. Seriam substituídos 9.928 ônibus rodoviários. As tabelas 4 e 5 apresentam os resultados obtidos.

Tabela 4. Reduções de emissões de óxidos de nitrogênio $\left(\mathrm{NO}_{\mathrm{x}}\right)$ na região metropolitana de São Paulo (ano base: 2017), com a introdução de veículos novos fase P8.

\begin{tabular}{|c|c|c|c|}
\hline Região Metropolitana de São Paulo (ano base 2017) & antes da troca da frota & depois da troca da frota & Redução \\
\hline Categoria/Poluente & NOx (toneladas) & NOx (toneladas) & NOx (toneladas) \\
\hline Ônibus Rodoviários & 2.259 & 375 & 1.884 \\
\hline
\end{tabular}

Tabela 5. Reduções de emissões de material particulado (MP) na região metropolitana de São Paulo (ano base: 2017), com a introdução de veículos novos fase P8.

\begin{tabular}{|c|c|c|c|}
\hline Região Metropolitana de São Paulo (ano base 2017) & antes da troca da frota & depois da troca da frota & Redução \\
\hline Categoria/Poluente & MP (toneladas) & MP (toneladas) & MP (toneladas) \\
\hline Ônibus Rodoviários & 67 & 4 & 63 \\
\hline
\end{tabular}

\section{CONCLUSÃO}

As frotas circulantes de ônibus e caminhões do município de São Paulo diminuíram $5 \%$ entre 2006 a 2017. Mas na região metropolitana de São Paulo, a mesma frota cresceu cerca de $32 \%$ no período. Ainda assim, os resultados das emissões de ônibus e caminhões de óxidos de nitrogênio $\left(\mathrm{NO}_{\mathrm{x}}\right)$ e material particulado (MP), provenientes de ônibus e caminhões, diminuíram no município de São Paulo e na região metropolitana de São Paulo, no período de 2006 a 2017.

Para a frota de ônibus e caminhões, as emissões de dióxido de carbono equivalente $\left(\mathrm{CO}_{2} \mathrm{eq}\right)$ aumentaram tanto no município de São Paulo quanto na RMSP neste 
período, deve-se ressaltar que estas emissões são obtidas em função do consumo de combustíveis fósseis e renováveis. No cálculo das emissões de dióxido de carbono equivalente $\left(\mathrm{CO}_{2}\right.$ eq) são consideradas as emissões de metano $\left(\mathrm{CH}_{4}\right)$ e óxido nitroso $\left(\mathrm{N}_{2} \mathrm{O}\right)$, porém estas emissões representam menos de $0,5 \%$ das emissões totais de $\mathrm{CO}_{2}$ eq do município e da região metropolitana de São Paulo.

Com a introdução de veículos da fase P8 do PROCONVE na frota circulante de ônibus da cidade de São Paulo, pode-se concluir que haverá a diminuição significativa das emissões de poluentes locais. Considerando o ano base de 2017, pode-se reduzir as emissões de $\mathrm{NO}_{x}$ em 3474 toneladas anuais e as emissões de material particulado (MP) em 146 toneladas anuais, adotando a troca de ônibus com mais de 10 anos.

E com a introdução de veículos da fase P8 do PROCONVE na frota circulante de ônibus fretados da região metropolitana de São Paulo, também se pode concluir que haverá a diminuição significativa das emissões de poluentes locais. Pode-se reduzir as emissões de $\mathrm{NO}_{x}$ em 1884 toneladas anuais e as emissões de material particulado (MP) em 63 toneladas anuais, adotando a troca de 9.928 veículos antigos, considerando o ano base de 2017.

\section{REFERÊNCIAS}

[1] DAPPER, S.N.;SPOHR,C; ZANINI, R.R.. Poluição do Ar como Fator de Risco para a Saúde, Estudos Avançados. São Paulo, volume 30, número 86, página 8397, Abril, 2016.

[2] USEPA. Research on Near Roadway and Other Near Source Air Pollution. https://www.epa.gov/air-research/research-near-roadway-and-other-near-source-airpollution. Acesso em: 06 mai 2019.

[3] CETESB. Emissões Veiculares no Estado de São Paulo 2017, São Paulo, SP, 2018. 213 p. Disponível em: < https://cetesb.sp.gov.br/veicular/wpcontent/uploads/sites/6/2019/02/Relat\%C3\%B3rio-Emiss\%C3\%B5es-Veiculares2017.pdf. Acesso em:14 mai. 2019.

[4] SÃO PAULO (Município) Lei Ordinária 16802/2018 de São Paulo (SP). Disponível em: https://leismunicipais.com.br/a/sp/s/sao-paulo/leiordinaria/2018/1680/16802/lei-ordinaria-n-16802-2018-da-nova-redacao-ao-art-50da-lei-n-14933-2009-que-dispoe-sobre-o-uso-de-fontes-motrizes-de-energia-menospoluentes-e-menos-geradoras-de-gases-do-efeito-estufa-na-frota-de-transportecoletivo-urbano-do-municipio-de-sao-paulo-e-da-outras-providencias. Acesso em: 14/05/2019.

[5] BRASIL CONAMA $\mathbf{n}^{\circ}$ 490/2018 Estabelece a Fase PROCONVE P8 de exigências do Programa de Controle da Poluição do Ar por Veículos Automotores - 
PROCONVE para o controle das emissões de gases poluentes e de ruído para veículos automotores pesados novos de uso rodoviário e dá outras providências. Disponível em: https://pesquisa.in.gov.br/imprensa/jsp/visualiza/index.jsp?data $=21 / 11 / 2018 \&$ jornal $=5$ 15\&pagina $=153 \&$ totalArquivos=178. Acesso em: 14/05/2019.

[6] SÃO PAULO (Estado). Secretaria de energia e mineração. Anuário energético por município - estado de São Paulo - 2018, ano base 2017. São Paulo, 2018. $121 \mathrm{p}$. Disponível em:

http://dadosenergeticos.energia.sp.gov.br/portalcev2/intranet/BiblioVirtual/diversos/a nuario_energetico_municipio.pdf >. Acesso em: 09 nov. 2018.

[7] ANFAVEA. Estatísticas. Dados relativos a 2017: produção, vendas, exportação produção, vendas e exportação de autoveículos. São Paulo, 2018. Disponível em $<$ http://www.anfavea.com.br/tabelas.html>.Acesso em: 29 jul. 2018.

[8] ANP. Anuário Estatístico Brasileiro do Petróleo, Gás Natural e Biocombustíveis - Índice. (Anuários dos anos de 2006 a 2017). Disponível em <http://anp.gov.br/?id=661> Acesso em: 29 ago. 2018.

[9] CETESB. Curvas de intensidade de uso por tipo de veículo automotor da frota da cidade de São Paulo. São Paulo, SP, 2013. 67 p. (Série Relatórios). Disponível em: <http://veicular.cetesb.sp.gov.br/wpcontent/uploads/sites/35/2013/12/curvas-intensidade-uso-veiculos-automotorescidade-sao-paulo.pdf >. Acesso em: 29 ago. 2016.

[10] DETRAN/SP. Frota de veículos em São Paulo, São Paulo, 2016. Disponível em:http://www.detran.sp.gov.br/wps/portal/portaldetran/detran/estatisticastransito/safrotaveiculos > Acesso em 10 abr. 2017.

[11] IBAMA. Programa de controle da poluição do ar por veículos automotores - PROCONVE (PROGRAMA DE CONTROLE DA POLUIÇÃO DO AR POR VEÍCULOS AUTOMOTORES)/PROMOT/IBAMA. $3^{\text {a }}$ ed. Brasília: Ibama/Diqua, 2011. Disponível em: <http://www.ibama.gov.br/phocadownload/category/4?download=4792\%3Amanualportugues >. Acesso em: 01 fev. 2017.

[12] EMTU Dados de frota. Disponível em: http://www.emtu.sp.gov.br/emtu/itinerarios-e-tarifas/outras-buscas/busca-por-dadoscadastrais-de-empresas-regulares-e-de-fretamento.fss. Acesso em:20 mai 2019. 